\title{
Toddler-directed and adult-directed gesture frequency in monolingual and bilingual caregivers
}

\author{
Monika Molnar $^{1,2}$, Kai Ian Leung ${ }^{1,2}$, Jodee Santos Herrera ${ }^{1}$, \& Marcel Giezen ${ }^{3}$ \\ ${ }^{1}$ Department of Speech-Language Pathology, University of Toronto, CANADA \\ ${ }^{2}$ Rehabilitation Sciences Institute, Faculty of Medicine, University of Toronto, CANADA \\ ${ }^{3}$ Basque Center on Cognition, Brain and Language, Donostia, SPAIN
}

\begin{abstract}
Author Note
This research was funded by the Canadian Natural Sciences and Engineering Grant (RGPIN2019-06523) to MM, and the Ayuda Centro de Excelencia Severo Ochoa SEV-2015-0490 grant awarded to the BCBL.
\end{abstract}


Abstract

\section{Aims and Objectives}

This study was designed to assess whether bilingual caregivers, compared to monolingual caregivers, modify their nonverbal gestures to match the increased communicative and/or cognitive-linguistic demands of bilingual language contexts - as would be predicted based on the Facilitative Strategy Hypothesis.

\section{Methodology}

We recorded the rate of gestures (i.e., representational and beat gestures) in monolingual and bilingual caregivers when they retold a cartoon story to their child or to an adult, in a monolingual and a bilingual context ('synonym’ context for monolingual caregivers).

\section{Data and Analysis}

We calculated the frequency of all gestures, representational gestures, and beat gestures for each addressee (adult-directed vs. toddler-directed) and linguistic context (monolingual vs. bilingual/synonym), separately for the monolingual and the bilingual caregivers. Using Linear Mixed Models, we contrasted monolingual vs. bilingual caregivers' gesture frequency.

\section{Findings/Conclusions}

Bilingual caregivers gesture more than monolingual caregivers, irrespective of addressee and language context. Furthermore, we found evidence in support of the Facilitative Strategy hypothesis across both monolingual and bilingual caregivers, as all caregivers increased the rate of their representational gestures in the child-directed re-telling. Furthermore, both bilingual and 
monolingual caregivers used more gestures in the context of increased communicative demands (bilingual context or using synonyms for monolingual caregivers).

\section{Originality}

To our knowledge, this is the first study of gesture use in child-directed communication in monolingual and bilingual caregivers.

\section{Significance/Implications}

Independent of their monolingual or bilingual status, caregivers adjust their multimodal communication strategies (specifically gestures) when interacting with their children. Furthermore, both monolingual and bilingual caregivers increase their gesture rate when communicative demands are higher.

Keywords: bilingualism, caregivers, multimodal communication, gesture rate, representational gestures, beat gestures 


\section{Toddler-directed and adult-directed gesture frequency in monolingual and bilingual caregivers}

Nonverbal gestures, including hand and arm movements, co-produced with spoken language, benefit speakers as well as listeners as they can shape the information that is conveyed and improve communication success (e.g., Hostetter, Pouw, \& Wakefield, 2020; Kelly \& Church, 1997; Wakefield, Novack, Congdon, \& Howard, 2021) ${ }^{1}$. In line with this communicative function of gestures, caregivers of children not only adjust their spoken language (i.e., infant-directed speech or motherese) to meet their child's communication needs, but their gestures as well (e.g., Iverson, Capirci, Longobardi, \& Caselli, 1999; Wermelinger, Gampe, Helbling \& Daum, 2020). Child or infant-directed gestures integrated with speech are often referred to as 'multimodal motherese' (e.g., Gogate, Bahrick, \& Watson, 2000). Here, we are going to refer to this as child-directed multimodal communication.

The Facilitative Strategy hypothesis posits that caregivers modify their multimodal childdirected communication to maximize communication success, and to support comprehension and learning in their children (e.g., Iverson \& Goldin-Meadow, 2005; Iverson et al., 1999; but see, O’Neill, Bertenthal, Cole, \& Gallagher, 2005 for an alternative view that gestural modification by caregivers may reflect semantic simplicity in caregiver-child interaction). Accordingly, with very young children (up to 2 years old) multimodal child-directed communication is characterized by fewer representational gestures and emphatic gestures, and more pointing gestures (Iverson et al. ', 1999; O’Neill et al., 2005), mirroring children’s own gesture production

\footnotetext{
${ }^{1}$ This includes deictic gestures (e.g., pointing), conventional gestures (gestures with a culturally defined meaning like the 'thumbs up' gesture), representational/iconic gestures (gestures referring to objects, locations, events), and emphatic ('beat') gestures (non-representational gestures highlighting discourse and content of speech).
} 
at that age; increased motion gestures to aid verb comprehension (Gogate et al., 2000); and the use of gestures that facilitate the comprehension of pragmatic intention (Esteve-Gibert, Prieto, \& Liszkowski, 2017). Across different cultures, multimodal child-directed communication is positively associated with children's multimodal communication and language development: children of caregivers that gesture frequently also gesture more frequently themselves (Liszkowski, Brown, Callaghan, Takada, \& De Vos, 2012); the frequency of caregivers' pointing is related to growth in vocabulary production (Iverson et al., 1999; Pan, Rowe, Singer, \& Snow, 2005); and increased parental representational gestural input may result in higher language measure scores in toddlers (Goodwyn, Acredolo, \& Brown, 2000). Furthermore, caregivers' verbal translations of child gestures identifying referents positively affect vocabulary development in both monolingual and bilingual children (Limia, Özçalişkan, \& Hoff, 2019).

According to the Facilitative Strategy hypothesis, caregivers should adjust their communicative behaviour (including their gestures) when the child requires additional support (Iverson \& Goldin-Meadow, 2005). In line with this prediction, Grimminger and colleagues (2010) reported higher gesture frequency in caregivers of late talkers than caregivers of typically developing children. This was observed for both more vs. less demanding linguistic contexts. During the more demanding linguistic context, both groups of caregivers increased their gesture rate. Furthermore, during a complex interactive problem-solving task, caregivers of children diagnosed with Developmental Language Disorder (Wray \& Norbury, 2018) and Down Syndrome (Iverson, Longobardi, Spampinto, \& Caselli, 2006) exhibited higher gesture rate compared to the caregivers of typically developing children. Therefore, it appears that caregivers are most likely to adjust their multimodal child-directed communication in the context of increased communication needs. 
More generally, it has been suggested that gesturing can save cognitive resources for both speakers and listeners (e.g., Alibali, Flevares, \& Goldin-Meadow, 1997; Ping \& GoldinMeadow, 2010). From the perspective of the speaker, gestures might play a role in alleviating working memory load, particularly when the described objects or ideas are absent (e.g., Krauss, Chen, \& Gotfexnum, 2000; Ping \& Goldin-Meadow, 2010). Furthermore, Melinger and Kita (2007) investigated whether the load on conceptualization processes for speakers affected their gesture rate. They compared gesture rates while speakers were describing pictures that varied in conceptualization load (picture of circles following a deterministic path - low load vs. picture of circles following a non-deterministic path - heavy load), and found that the heavy load condition was associated with a higher gesture rate than the low load condition.

Additional support for the idea that communicative demands and cognitive load are associated with increased gesture production comes from studies of bilinguals. For example, some studies have found that gesture use by adult bilinguals is related to their proficiency in each language (see Nicoladis, 2007 for a review). Similarly, Nicoladis et al. (1999) found that the use of iconic and beat gesture production increased with age and was correlated with the mean length of utterance in each language. In addition, several studies reported that bilinguals gesture more than monolinguals, which has been linked to relative differences in language proficiency, or alternatively, might be due to more general increased cognitive load associated with bilingual language use (Alibali et al., 1997; Ping \& Goldin-Meadow, 2010; Smithson \& Nicoladis, 2013). Here, we aim to gain further insight on gesture use in bilinguals by investigating whether the Facilitative Support Hypothesis applies to a bilingual learning context 'more' than to a monolingual learning context. Specifically, if caregivers perceive a bilingual learning context as more difficult than a monolingual learning context, they would gesture more in a bilingual 
context than a monolingual context with their children, but not with another adult. Some preliminary support for this hypothesis comes from a recent study showing that, parents of Swiss German bilingual children produced more iconic gestures than parents of Swiss-German monolingual children in a gesture reproduction task that required participants describing different actions in the language of their choice to an experimenter (Wermelinger et al., 2020). However, this may also have been due to the fact that parents who spoke other languages gestured more than Swiss German speaking parents.

\section{Current Study}

The current study was designed to gain further insight into the effects of communicative context and cognitive-linguistic demands on gesture production in bilingual caregivers. To this end, we investigated how bilingual caregivers modify their gesture depending on the addressee (own toddler vs. adult) and cognitive-linguistic demands, specifically whether they are re-telling a story using one language (monolingual context) vs. re-telling a story using both of their languages (bilingual context), as compared to monolingual caregivers.

According to the Facilitative Strategy hypothesis, gesture is a key element of parent-child communication and the communicative environment provided by caregivers is thought to support language development (e.g., Iverson et al., 1999; Iverson \& Goldin-Meadow, 2005; Puccini, Hassemer, Salomo, \& Liszkowski, 2010). Here, we test whether bilingual caregivers adjust their gestures depending on addressee (toddler- vs adult-directed) and cognitive-linguistic context (monolingual vs. bilingual/synonym condition). First, given reports in the literature that bilinguals tend to gesture more than monolinguals (Gullberg, 2013; Nicoladis et al., 2007), we expect to see a higher gesture rate in bilingual caregivers compared to monolingual caregivers across all conditions. Second, if caregivers believe that a bilingual context (when both languages 
are used) is more difficult for a child than a monolingual context, they might compensate for this by using more gestures, in particular representational gestures. In that case, we would expect to find a higher gesture rate for bilingual caregivers in the bilingual toddler-directed context compared to the adult-directed bilingual context. This finding would be in line with previous reports that caregivers of children with special communication needs tend to gesture more to match their child's needs (Grimminger et al., 2010; Iverson et al., 2006; Wray \& Norbury, 2018). In addition, it has been shown that gestures can improve learning, which may be particularly relevant for bilingual children, because gestures are not linked to a specific language (Church, Ayman-Nolley, \& Mahootian, 2004). This idea is in line with the Bilingual Dual-Coding theory, which posits that bilinguals have words encoded by two sets of verbal representations, one for each language, and these two verbal representations are linked to one separate imagery system (Paivio, Clark, \& Lambert, 1988). Bilingual caregivers might therefore be especially more likely to use representational gestures in a 'bilingual context' compared to a 'monolingual context'. Finally, given that increased task complexity and cognitive load have been associated with higher gesture rate, it is possible that both the bilingual and synonym conditions - as cognitively more complex conditions - elicit more representational and emphatic ('beat') gestures than the monolingual condition (cf., Melinger \& Kita, 2007).

\section{Methods}

\section{Participants}

All of our participants were recruited from the Spanish-Basque bilingual region of the Basque Country in Northern Spain, which provides an ideal test bed for contrasting gestures across monolingual and bilingual speakers. Gesture rate correlates with cultural background and 
story-retelling styles in bilinguals (Nicoladis, Nagpal, Marentette, \& Hauer, 2018). By recruiting monolingual and bilingual participants from the same cultural background, we aimed to minimize differences between the groups in gestural behaviour and storytelling styles.

We recruited 12 Spanish-Basque simultaneous bilingual and 11 Spanish monolingual female caregivers with a child between the ages of 30 and 36 months. This sample size per group is comparable to previous studies investigating gesture frequency in monolingual/bilingual populations (e.g., Pika, Nicoladis, Marentette, 2006). All caregivers were living in the San Sebastián region of the Basque Country, Spain. Their language background was evaluated using a version of the LEAP-Q questionnaire (Marian, Blumenfeld, \& Kaushanskaya, 2007) adapted for use in the Basque Country. The simultaneous bilingual caregivers began to learn both Spanish and Basque before the age of 3 and did not use a third language regularly. They also reported to use both of their languages regularly with their family and friends. The monolingual Spanish caregivers grew up in a monolingual Spanish-speaking household and did not report using other languages on a regular basis. Data from four caregivers were excluded from analysis due to incomplete filming of sessions $(n=2)$, or because they did not produce any gestures during the sessions $(\mathrm{n}=2)$. The final sample of caregivers consisted of 11 simultaneous bilinguals and 8 monolinguals.

\section{Procedure}

Participants were asked to retell stories from cartoon videos (Canary Row), as speakers are more likely to gesture when talking about objects and ideas that are not present and have to be recalled from a video stimulus (e.g., Hostetter \& Hopkins, 2002; Morsella \& Krauss, 2004). Caregivers completed two testing sessions on two separate days around one week apart: one session in a monolingual context, and one session in a bilingual or synonym context. Participants 
always completed the monolingual context first, and the order of adult vs. toddler-directed conditions were counterbalanced across the caregivers. In each session, the caregivers watched and retold two clips of the Canary Row cartoon to an adult addressee (adult-directed) and to their own child as addressee (child-directed). During the adult-directed story re-telling, the caregiver retold two cartoons to a research assistant (while the child was absent); during the child-directed story re-telling, the caregivers retold two cartoons to the child. In total, eight cartoons were used, which were counterbalanced across addressees and linguistic contexts. A practice cartoon was used at the start of the child-directed and adult-directed story re-tellings to familiarize caregivers with the task and the addressee.

In the monolingual context, bilingual caregivers were told to use the language they felt the most comfortable with (this was always Spanish) and the monolingual caregivers used their only native language (Spanish). Monolingual and bilingual caregivers were given the same instructions in their monolingual testing condition. As verbal cue to the language context, the caregivers were given two specific Spanish target verbs ('labels'), relevant to the given cartoon, to include in their story re-telling. In the bilingual context, the bilingual caregivers were encouraged to use both of their languages (i.e., code-switching). To stimulate the use of both languages, they were given two labels in both languages as verbal cues, to include in story retelling. To create a (more or less) parallel context for the monolingual caregivers and control for the increased number of target verbs in the bilingual condition, in the synonym context the monolingual caregivers were given two Spanish synonyms for the same labels and encouraged to include both synonyms in their story re-telling. These labels are listed in Appendix A. 
The caregivers were seated in a comfortable chair in front of a small table. On the small table, there was an iPad that they used for watching the cartoons. Each testing session was recorded using two cameras. One camera was directed at the caregiver, which was used for coding the caregivers' gestures, while the other camera was directed at the addressee.

\section{Gesture Coding}

As story-retelling is less likely to elicit pointing gestures than representational gestures (gestures with a meaningful relation to the semantic content of the retold story) and beat gestures (motor gestures consisting of simple, repetitive, rhythmic hand/arm movements without any obvious semantic content), our analyses focused on the latter two gesture types, in addition to overall gesture rate.

Two experimenters independently coded videos using the ELAN software (Version 5.3), a tier-based system for the annotation and transcription of audio and video. Only communicative movements by the hands and/or arms were coded for as gestures. Grooming and head/body movements were not coded. Annotations of the identified gestures were aligned with the gesture onset and offset. All our raw data, including the annotated files, are available on the following OSF page: <https://osf.io/nt935/>

Each gesture was coded for type: beat, representational or other gestures. Beat gestures were defined as simple, rhythmic, non-representational movements of the hands, which help facilitate or emphasize certain aspects of speech. Representational gestures were defined as hand movements that indicate an iconic, or metaphoric representation of the speaker's dialogue. Other gestures included, for example, pointing gestures and gestures that could not be clearly categorized as either beat gestures or representational gestures. 


\section{Inter-rater reliability}

Inter-rater reliability of gesture coding was evaluated by computing the agreement in coding of gesture type between the two coders across sixteen video files. Datasets of two monolingual and two bilingual caregivers were chosen randomly for the inter-rater comparison, representing $21 \%$ of participants. Inter-rater reliability was found to be $86 \%$ for gesture type across the sixteen videos. Any disagreements between coders were resolved following discussion.

\section{Results}

Gesture rate was calculated by counting the number of gestures (i.e., overall, representational and beat gestures) participants produced during their retelling of the cartoon, divided by the number of words uttered by a given participant. We multiplied the values by 100 , to simplify the presentation of the numbers. Tables 1,2, and 3 show gesture rate for all gestures, representational gestures, and beat gestures, respectively, across addressee and language contexts. Other gestures were not included in these analyses, as there were few instances of this category (4\% of total gestures). We ran linear mixed effects models, separately for all gestures, representational and beat gesture rate, using Jamovi (version 1.8), GAMLj package (version 2.4.7). For each dependent variable model, we included fixed effects of group (monolingual, bilingual caregivers), addressee (child-directed, adult-directed) and language context (monolingual, bilingual/synonym), and their interactions and a random effect of participant. For each model, all fixed effect estimates and box plots are presented in the Supplementary Materials.

\section{All Gestures}


The data are presented in Table 1 and Figure 1. A linear mixed effects model was conducted to examine the effect of group (monolingual vs. bilingual caregivers), addressee (child-directed, adult-directed), context (monolingual vs. bilingual/synonym) and their interactions on the rate of all gestures. Bilinguals generally gestured more than monolinguals $(\beta=$ $-0.03, \mathrm{t}=-2.40, \mathrm{p}=0.02)$. Gesture rate was higher in the bilingual/synonym context, compared to the monolingual context $(\beta=0.02, \mathrm{t}=2.58, \mathrm{p}=0.01)$. No effect of addressee and no interactions were found. Fixed effect estimates are presented in the Supplementary Materials.

\section{Representational Gestures}

The data are presented in Table 2 and Figure 2. A linear mixed effects model was conducted to examine the effect of group, addressee group, context and their interactions on the rate of representational gestures. Representational gesture rate was higher in the bilingual/synonym context $(\beta=1.88, \mathrm{t}=3.44, \mathrm{p}=0.001)$ and towards child addressees $(\beta=-$ $1.81, \mathrm{t}=-3.31, \mathrm{p}=0.002)$. No effect of group and no interactions were found. Fixed effect estimates are presented in the Supplementary Materials.

\section{Beat Gestures}

The data are presented in Table 3 and Figure 3. A linear mixed effects model was conducted to examine the effect of addressee, group, language context and their interactions on the rate of beat gestures. Bilinguals generally used more beat gestures than monolinguals $(\beta=$ $1.96, t=-2.24, \mathrm{p}=0.03)$. Higher gesture rate was observed towards adult addressees $(\beta=2.60, \mathrm{t}$ $=4.50, \mathrm{p}=<.001)$. No effect of context and no interactions were found. Fixed effect estimates, are presented in the Supplementary Materials. 


\section{Discussion}

The main goal of our study was to test whether the Facilitative Strategy hypothesis can be extended to bilingual communicative contexts. It has been observed that caregivers of children with special communication needs such as Developmental Language Disorder or Down Syndrome tend to gesture more, presumably to support their child's increased communication needs (Grimminger et al., 2010; Iverson et al., 2006; Wray \& Norbury, 2018) - in line with the Facilitative Strategy hypothesis. Specifically, our study was designed to assess whether bilingual caregivers, compared to monolingual caregivers, modify their child-directed multimodal communication to match the increased communicative and/or cognitive-linguistic demands of bilingual language contexts. To address this question, we recorded the rate of representational and beat gestures in monolingual and bilingual caregivers when they retold a cartoon story to their child or an adult in a monolingual and a bilingual context ('synonym' context for monolingual caregivers).

A comparison of overall gesture rate across the two groups showed that bilinguals generally gestured more than monolinguals, irrespective of linguistic context (monolingual vs. bilingual) or addressee (toddler vs. adult). This is in line with prior observations of higher gesture frequency in bilinguals, especially in their weaker language (Gullberg, 2013). Our findings are in line with Wermelinger et al. (2020), who found that parents of Swiss German bilingual children parents produced more iconic gestures than parents of Swiss German monolingual children in a gesture reproduction task in their language of choice (presumably their dominant language). Our study extends these findings by showing that bilingual adults gesture more in their language of choice as well as in a bilingual context - and when communicating both in adult-directed and toddler-directed situations. Whether gesture rate is (also) affected by 
interlocutor familiarity is unclear, as our adult interlocutor was unfamiliar to all of our participants, while the toddler interlocutor was not. Therefore, in contrast to some previous findings (see Gullberg, 2013 for a review), our results suggest that in a story re-telling paradigm, bilinguals gesture more than monolinguals in their stronger language and when using both of their languages - not just when they are using their weaker language.

The finding that monolingual and bilingual caregivers gestured more in the bilingual/synonym context as compared to the monolingual context may reflect higher cognitive load for the bilingual/synonym context, which may lead to increased gesture use (e.g., Hoetjes \& Masson-Carro, 2017; Melinger \& Kita, 2007). This effect seems more pronounced in the childdirected setting, suggesting that child-directed gesture might be especially sensitive to task demands.

Our analyses of beat gestures revealed that bilinguals also used more beat gestures than monolinguals. This is consistent with the idea that bilinguals increased their gesture frequency because of higher cognitive demands, in particular given that beat gestures have been suggested to boost attention and facilitate semantic integration (e.g. Biau \& Soto-Faraco, 2013; Dimitrova, Chu, Wang, Özyürek, \& Hagoort, 2016; but also see discussion by Rohrer, Delais-Roussarie, \& Prieto, 2020). In addition, both monolingual and bilingual caregivers used more beat gestures in the adult-directed vs. child-directed setting. This is in line with prior observations that beat gestures are relatively infrequent in parental input to young children and appear late in children's gesture production (McNeill, 1992; McNeill et al., 2005).

The finding that the bilinguals produced more representational and beat gestures than monolinguals in the monolingual context as well as the bilingual context may seem somewhat paradoxical. In particular, while the use of both languages in the bilingual context might be 
expected to lead to increased language demands for bilinguals, this is less apparent for the monolingual context. However, we speculate that increased gesture use by bilinguals in a monolingual context might be explained by parallel language activation (e.g., Kroll \& Bialystok, 2013). Even when bilinguals are only using one of their languages, both of their languages are active, therefore bilinguals must allocate attentional resources (e.g., inhibitory control) to select the appropriate language for communication, as opposed to the competing language. This additional cognitive load in the monolingual context could explain the higher gesture rate for bilinguals. While the cognitive load associated with parallel language activation is likely to be lower in the bilingual context, language coordination demands increase due to the availability of code-switching and the increased task demands from having to use two target labels in both languages instead of two target labels in one language only.

Further evidence for a compensatory relationship between gesture rate and cognitive demands comes from studies showing a negative relation between verbal working memory in both monolinguals and bilinguals. Smithson and Nicoladis (2013) examined the association between verbal working memory abilities and gesture production: in the monolingual group, verbal short-term memory had a negative relationship with iconic (or representational) gesture production, and in the bilingual French session, verbal working memory had a negative relationship with gesture production. These findings suggest that those with weaker verbal memory tend to use representational gestures more frequently; in addition, there might be a different relationship between gestures and working memory across monolinguals and bilinguals (Smithson \& Nicoladis, 2013). Chu and colleagues (2014) also found that participants with poorer visual and spatial working memory tended to gesture more. 
Finally, both monolingual and bilingual caregivers produced more representational gestures in the child-directed than adult-directed setting. This is in line with the predictions of the Facilitative Strategy hypothesis, as gesturing in the child-directed story re-telling could be considered as a form of multimodal child-directed communication. The caregivers increased their use of representational gestures to provide more semantic support for children than for adults. Representational gestures were also more common in the bilingual/synonym context, when the caregivers were asked to use more labels to describe the same concept. This suggests that when communication needs change, both monolingual and bilingual caregivers adjust their use of representational gestures.

In summary, bilinguals tend to gesture more than monolinguals irrespective of addressee and context. Furthermore, we found evidence in support of the Facilitative Strategy hypothesis across both monolingual and bilingual caregivers: both types of caregivers increased the rate of their representational gestures in the child-directed story re-telling. In addition, both groups of caregivers adjusted their gestures in the context of higher communicative demands (language switching for bilingual caregivers and synonym context for monolingual caregivers). However, we found no clear evidence for additional effects in bilingual caregivers in line with this hypothesis. Specifically, there were no clear patterns showing that bilingual caregivers, compared to monolingual caregivers, adjust their multimodal child-directed communication when their child is listening to a story in two languages. We therefore conclude that i) both monolingual and bilingual caregivers similarly adjust their gestures to aid their child's comprehension and when experiencing higher communicative demands, and ii) bilinguals generally gesture more than monolinguals. 


\section{References}

Alibali, M. W., Flevares, L. M., \& Goldin-Meadow, S. (1997). Assessing knowledge conveyed in gesture: Do teachers have the upper hand?. Journal of Educational Psychology, 89(1), 183-193.

Biau, E., \& Soto-Faraco, S. (2013). Beat gestures modulate auditory integration in speech perception. Brain and Language, 124(2), 143-152.

Chu, M., Meyer, A., Foulkes, L., \& Kita, S. (2014). Individual differences in frequency and saliency of speech-accompanying gestures: The role of cognitive abilities and empathy. Journal of Experimental Psychology: General, 143(2), 694-709.

Church, R. B., Ayman-Nolley, S., \& Mahootian, S. (2004). The role of gesture in bilingual education: Does gesture enhance learning?. International Journal of Bilingual Education and Bilingualism, 7(4), 303-319.

Cuevas, P., Steines, M., He, Y., Nagels, A., Culham, J., \& Straube, B. (2019). The facilitative effect of gestures on the neural processing of semantic complexity in a continuous narrative. NeuroImage, 195, 38-47.

Dimitrova, D., Chu, M., Wang, L., Özyürek, A., \& Hagoort, P. (2016). Beat that word: How listeners integrate beat gesture and focus in multimodal speech discourse. Journal of Cognitive Neuroscience, 28(9), 1255-1269.

ELAN (Version 5.3) [Computer software]. (2019). Nijmegen: Max Planck Institute for Psycholinguistics, The Language Archive. Retrieved from https://archive.mpi.nl/tla/elan 
Esteve-Gibert, N., Prieto, P., \& Liszkowski, U. (2017). Twelve-month-olds understand social intentions based on prosody and gesture shape. Infancy, 22(1), 108-129.

Giezen, M. R., Blumenfeld, H. K., Shook, A., Marian, V., \& Emmorey, K. (2015). Parallel language activation and inhibitory control in bimodal bilinguals. Cognition, 141, 9-25.

Gogate, L. J., Bahrick, L. E., \& Watson, J. D. (2000). A study of multimodal motherese: The role of temporal synchrony between verbal labels and gestures. Child Development, 71(4), 878-894.

Goodwyn, S. W., Acredolo, L. P., \& Brown, C. A. (2000). Impact of symbolic gesturing on early language development. Journal of Nonverbal Behavior, 24(2), 81-103.

Grimminger, A., Rohlfing, K. J., \& Stenneken, P. (2010). Children's lexical skills and task demands affect gestural behavior in mothers of late-talking children and children with typical language development. Gesture, 10(2-3), 251-278.

Gullberg, M. (2013). 17 Bilingualism and Gesture. In T. K. Bhatia \& W. C. Ritchie (Eds.), The handbook of bilingualism and multilingualism (2nd ed., pp. 417-437). Wiley Blackwell.

Hoetjes, M. W., \& Masson-Carro, I. (2017). Under load: The effect of verbal and motoric cognitive load on gesture production. Journal of Multimodal Communication Studies, 4, 29-35.

Hostetter, A. B., \& Hopkins, W. D. (2002). The effect of thought structure on the production of lexical movements. Brain and Language, 82(1), 22-29. 
Hostetter, A. B., Pouw, W., \& Wakefield, E. M. (2020). Learning from gesture and action: An investigation of memory for where objects went and how they got there. Cognitive Science, 44(9), e12889.

Iverson, J. M., Capirci, O., Longobardi, E., \& Caselli, M. C. (1999). Gesturing in mother-child interactions. Cognitive Development, 14(1), 57-75.

Iverson, J. M., \& Goldin-Meadow, S. (2005). Gesture paves the way for language development. Psychological Science, 16(5), 367-371.

Iverson, J. M., Longobardi, E., Spampinato, K., \& Caselli, M. C. (2006). Gesture and speech in maternal input to children with Down's syndrome. International Journal of Language \& Communication Disorders, 41(3), 235-251.

Kelly, S. D., \& Church, R. B. (1997). Can children detect conceptual information conveyed through other children's nonverbal behavior's. Cognition and Instruction, 15(1), 107-134.

Krauss, R. M., Chen, Y., \& Gotfexnum, R. F. (2000). 13 Lexical gestures and lexical access: a process model. In D. McNeill (Eds.), Language and gesture (pp. 261-283). Cambridge University Press.

Kroll, J. F., \& Bialystok, E. (2013). Understanding the consequences of bilingualism for language processing and cognition. Journal of Cognitive Psychology, 25(5), 497-514.

Limia, V., Özçalişkan, S., \& Hoff, E. (2019). Do Parents Provide a Helping Hand to Vocabulary Development in Bilingual Children?. Journal of Child Language, 46(3), 501-521. 
Liszkowski, U., Brown, P., Callaghan, T., Takada, A., \& De Vos, C. (2012). A prelinguistic gestural universal of human communication. Cognitive Science, 36(4), 698-713.

Marian, V., Blumenfeld, H. K., \& Kaushanskaya, M. (2007). The Language Experience and Proficiency Questionnaire (LEAP-Q): Assessing Language Profiles in Bilinguals and Multilinguals. Journal of Speech, Language, and Hearing Research, 50(4), 940-967.

McNeill, D. (1992). Hand and mind: What gestures reveal about thought. University of Chicago Press.

McNeill, D., Bertenthal, B., Cole, J., \& Gallagher, S. (2005). Gesture-first, but no gestures?. Behavioral and Brain Sciences, 28(2), 138-138.

Melinger, A., \& Kita, S. (2007). Conceptualisation load triggers gesture production. Language and Cognitive Processes, 22(4), 473-500.

Morsella, E., \& Krauss, R. M. (2004). The role of gestures in spatial working memory and speech. The American Journal of Psychology, 117(3), 411-424.

Nicoladis, E., Nagpal, J., Marentette, P., \& Hauer, B. (2018). Gesture frequency is linked to story-telling style: evidence from bilinguals. Language and Cognition, 10(4), 641-664.

Nicoladis, E., Pika, S., Yin, H., \& Marentette, P. (2007). Gesture use in story recall by ChineseEnglish bilinguals. Applied Psycholinguistics, 28(4), 721-735.

O'Neill, M., Bard, K. A., Linnell, M., \& Fluck, M. (2005). Maternal gestures with 20-month-old infants in two contexts. Developmental Science, 8(4), 352-359. 
Paivio, A., Clark, J. M., \& Lambert, W. E. (1988). Bilingual dual-coding theory and semantic repetition effects on recall. Journal of Experimental Psychology: Learning, Memory, and Cognition, 14(1), 163-172.

Pan, B. A., Rowe, M. L., Singer, J. D., \& Snow, C. E. (2005). Maternal correlates of growth in toddler vocabulary production in low-income families. Child Development, 76(4), 763782.

Ping, R., \& Goldin-Meadow, S. (2010). Gesturing saves cognitive resources when talking about nonpresent objects. Cognitive Science, 34(4), 602-619.

Pika, S., Nicoladis, E., \& Marentette, P. F. (2006). A cross-cultural study on the use of gestures: Evidence for cross-linguistic transfer?. Bilingualism: Language and Cognition, 9(3), 319327.

Puccini, D., Hassemer, M., Salomo, D., \& Liszkowski, U. (2010). The type of shared activity shapes caregiver and infant communication. Gesture, 10(2-3), 279-296.

Rohrer, P. L., Prieto, P., \& Delais-Roussarie, E. (2020). Beat gestures for comprehension and recall: Differential effects of language learners and native listeners. Frontiers in Psychology, 11, 575929-575929.

Smithson, L., \& Nicoladis, E. (2013). Verbal memory resources predict iconic gesture use among monolinguals and bilinguals. Bilingualism: Language and Cognition, 16(4), 934944. 
Wakefield, E. M., Novack, M. A., Congdon, E. L., \& Howard, L. H. (2021). Individual differences in gesture interpretation predict children's propensity to pick a gesturer as a good informant. Journal of Experimental Child Psychology, 205, 105069.

Wermelinger, S., Gampe, A., Helbling, N., \& Daum, M. M. (2020). Do you understand what I want to tell you? Early sensitivity in bilinguals' iconic gesture perception and production. Developmental Science, 23(5), e12943.

Wray, C., \& Norbury, C. F. (2018). Parents modify gesture according to task demands and child language needs. First Language, 38(4), 419-439. 
Table 1. Mean (SD) gesture rate for all gesture types by addressee, context and group.

\begin{tabular}{llcc} 
& & \multicolumn{2}{c}{ All Gestures } \\
\cline { 3 - 4 } Addressee & Context & Bilingual & Monolingual \\
\hline Child & Monolingual & $0.14(0.04)$ & $0.12(0.03)$ \\
& Bilingual/Synonym & $0.17(0.05)$ & $0.13(0.04)$ \\
& Total & $0.15(0.05)$ & $0.12(0.03)$ \\
\multirow{2}{*}{ Adult } & Monolingual & $0.17(0.05)$ & $0.10(0.03)$ \\
& Bilingual/Synonym & $0.17(0.05)$ & $0.14(0.04)$ \\
& Total & $0.17(0.05)$ & $0.12(0.04)$ \\
\hline Total & & $\mathbf{0 . 1 6 ( \mathbf { 0 . 0 5 } )}$ & $\mathbf{0 . 1 2 ( \mathbf { 0 . 0 3 } )}$ \\
\hline
\end{tabular}

Figure 1. Boxplots for all gesture rate: (A) All gesture rate by language group (Bilingual, Monolingual); (B) All gesture rate by addressee (Child, Adult); (C) All gesture rate by context (Monolingual, Bilingual/Synonym)

(A)

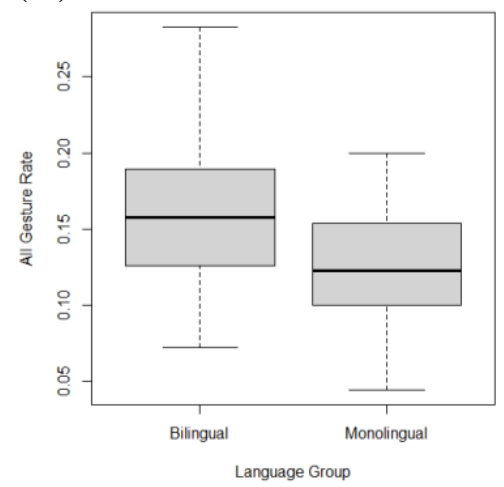

(B)

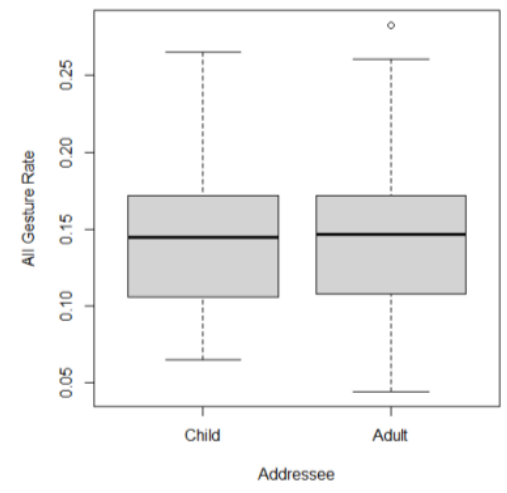

(C) 


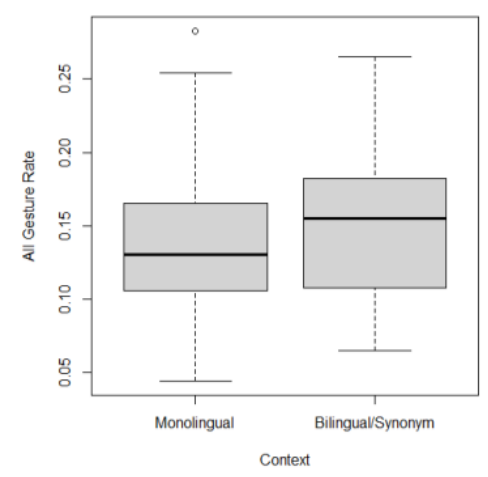

Table 2. Mean (SD) gesture rate for representational gestures by addressee, context and group.

\begin{tabular}{llcc} 
& & \multicolumn{2}{c}{ Representational Gestures } \\
\cline { 3 - 4 } Addressee & Context & Bilingual & Monolingual \\
\hline Child & Monolingual & $8.89(3.57)$ & $8.67(2.45)$ \\
& Bilingual/Synonym & $10.43(2.68)$ & $9.91(2.66)$ \\
& Total & $9.66(3.18)$ & $9.29(2.55)$ \\
\multirow{3}{*}{ Adult } & Monolingual & $7.73(2.57)$ & $5.27(2.64)$ \\
& Bilingual/Synonym & $9.01(3.37)$ & $8.69(4.18)$ \\
& Total & $8.40(3.01)$ & $6.98(3.81)$ \\
\hline \multirow{2}{*}{ Total } & & $\mathbf{9 . 0 4 ( 3 . 1 3 )}$ & $\mathbf{8 . 1 3}(\mathbf{3 . 4 0})$ \\
\hline
\end{tabular}

Figure 2. Boxplots for representational gesture rate. (A) Representational gesture rate by language group (Bilingual, Monolingual); (B) Representational gesture rate by addressee (Child, Adult); (C) Representational gesture rate by context (Monolingual, Bilingual/Synonym)

(A)

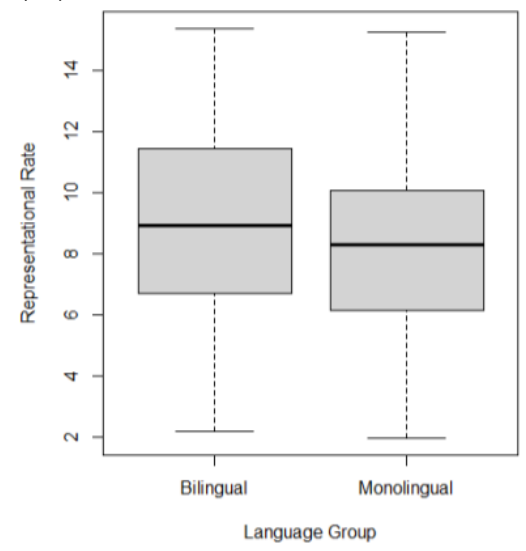

(B) 

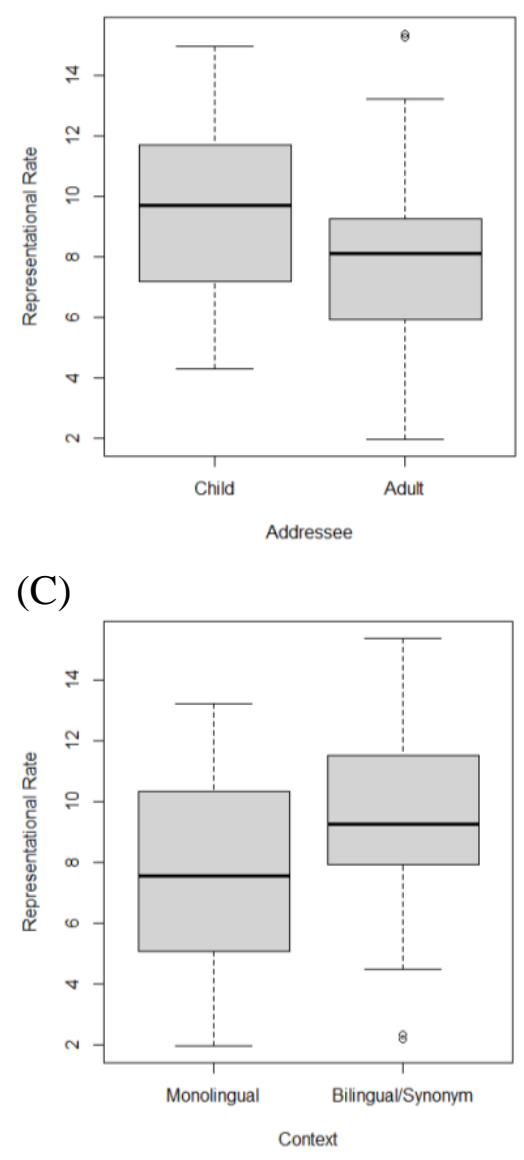

Table 3. Mean (SD) gesture rate for beat gestures by addressee, context and group.

\section{Beat Gestures}

\begin{tabular}{llcc} 
Addressee & Context & Bilingual & Monolingual \\
\hline Child & Monolingual & $3.44(1.76)$ & $2.44(2.14)$ \\
& Bilingual/Synonym & $4.07(2.68)$ & $2.76(2.70)$ \\
& Total & $3.76(2.24)$ & $2.60(2.36)$ \\
\multirow{3}{*}{ Adult } & Monolingual & $7.89(4.46)$ & $4.64(2.89)$ \\
& Bilingual/Synonym & $6.61(3.46)$ & $4.16(3.04)$ \\
& Total & $7.22(3.92)$ & $4.40(2.88)$ \\
\hline Total & & $\mathbf{5 . 4 5 ( 3 . 5 9 )}$ & $\mathbf{3 . 5 0}(\mathbf{2 . 7 4 )}$ \\
\hline
\end{tabular}


Figure 3. Boxplots for beat gesture rate: (A) Beat gesture rate by language group (Bilingual, Monolingual); (B) Beat gesture rate by addressee (Child, Adult); (C) Beat gesture rate by context (Monolingual, Bilingual/Synonym)

(A)

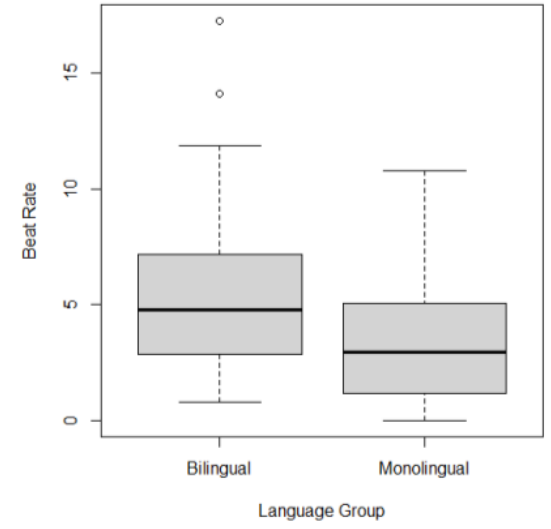

(B)

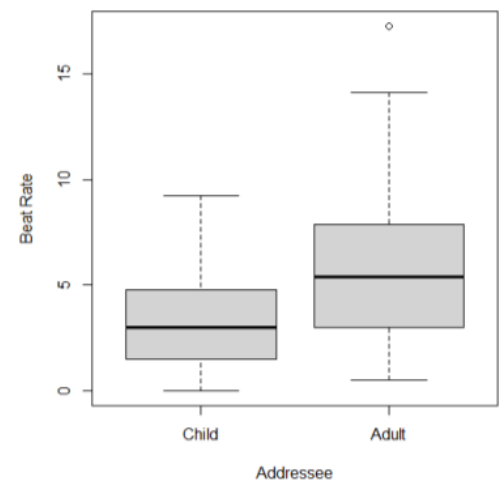

(C)

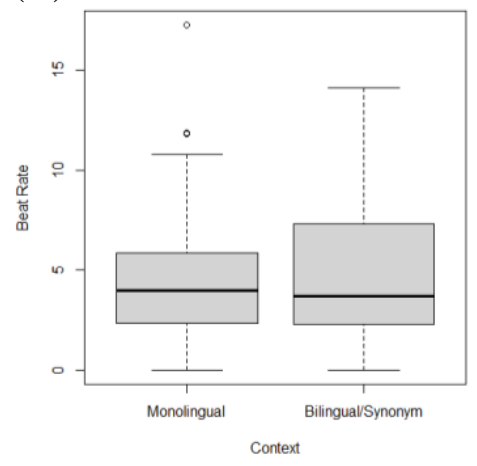


Appendix A. Spanish target labels and associated Basque translations and Spanish synonyms used in the study.

\begin{tabular}{|c|c|c|c|}
\hline clip & Spanish label & Basque translation & Spanish synonym \\
\hline \multirow[t]{4}{*}{ practice } & $\begin{array}{l}\text { dormir } \\
\text { (to sleep) }\end{array}$ & $\begin{array}{l}\text { lotan } \\
\text { (asleep) }\end{array}$ & $\begin{array}{l}\text { descansar } \\
\text { (to rest) }\end{array}$ \\
\hline & $\begin{array}{l}\text { esconderse } \\
\text { (to hide) }\end{array}$ & $\begin{array}{l}\text { ezkutatu } \\
\text { (hide) }\end{array}$ & $\begin{array}{l}\text { taparse } \\
\text { (to cover) }\end{array}$ \\
\hline & $\begin{array}{l}\text { botar } \\
\text { (to throw away) }\end{array}$ & $\begin{array}{l}\text { boteak eman } \\
\text { (give the boots) }\end{array}$ & $\begin{array}{l}\text { dar saltos } \\
\text { (jumps) }\end{array}$ \\
\hline & atascarse & erori & atrapar \\
\hline 1 & $\begin{array}{l}\text { mirar } \\
\text { (to look at) }\end{array}$ & $\begin{array}{l}\text { begiratu } \\
\text { (look) }\end{array}$ & $\begin{array}{l}\text { espiar } \\
\text { (to spy) }\end{array}$ \\
\hline & $\begin{array}{l}\text { echar } \\
\text { (to throw) }\end{array}$ & $\begin{array}{l}\text { bota } \\
\text { (throw) }\end{array}$ & $\begin{array}{l}\text { expulsar } \\
\text { (to eject) }\end{array}$ \\
\hline 2 & $\begin{array}{l}\text { columpiarse } \\
\text { (to swing) }\end{array}$ & $\begin{array}{l}\text { kulunkatu } \\
\text { (rocking) }\end{array}$ & $\begin{array}{l}\text { mover } \\
\text { (to move) }\end{array}$ \\
\hline & $\begin{array}{l}\text { perseguir } \\
\text { (to chase) }\end{array}$ & $\begin{array}{l}\text { segitu } \\
\text { (follow) }\end{array}$ & $\begin{array}{l}\text { ir detras de } \\
\text { (to go after) }\end{array}$ \\
\hline 3 & $\begin{array}{l}\text { tirar } \\
\text { (to throw) }\end{array}$ & $\begin{array}{l}\text { bota } \\
\text { (throw) }\end{array}$ & $\begin{array}{l}\text { meter } \\
\text { (to put) }\end{array}$ \\
\hline & $\begin{array}{l}\text { tragar } \\
\text { (to swallow) }\end{array}$ & $\begin{array}{l}\text { irentsi } \\
\text { (swallow) }\end{array}$ & $\begin{array}{l}\text { comer } \\
\text { (to eat) }\end{array}$ \\
\hline 4 & $\begin{array}{l}\text { engañar } \\
\text { (to trick) }\end{array}$ & $\begin{array}{l}\text { gezurra esan } \\
\text { (lie) }\end{array}$ & $\begin{array}{l}\text { mentir } \\
\text { (to lie) }\end{array}$ \\
\hline & $\begin{array}{l}\text { disfrazarse } \\
\text { (to disguise) }\end{array}$ & $\begin{array}{l}\text { mozorrotu } \\
\text { (disguise) }\end{array}$ & $\begin{array}{l}\text { fingir } \\
\text { (to pretend) }\end{array}$ \\
\hline
\end{tabular}




\begin{tabular}{|c|c|c|c|}
\hline \multirow[t]{2}{*}{5} & $\begin{array}{l}\text { escuchar } \\
\text { (to listen to) }\end{array}$ & $\begin{array}{l}\text { entzun } \\
\text { (hear or listen) }\end{array}$ & $\begin{array}{l}\text { oir } \\
\text { (to hear) }\end{array}$ \\
\hline & $\begin{array}{l}\text { robar } \\
\text { (to steal) }\end{array}$ & $\begin{array}{l}\text { lapurtu } \\
\text { (steal) }\end{array}$ & $\begin{array}{l}\text { llevar } \\
\text { (to take away) }\end{array}$ \\
\hline \multirow[t]{2}{*}{6} & $\begin{array}{l}\text { saltar } \\
\text { (to jump) }\end{array}$ & $\begin{array}{l}\text { salto egin } \\
\text { (jump) }\end{array}$ & $\begin{array}{l}\text { salir disparado } \\
\text { (to shoot out) }\end{array}$ \\
\hline & $\begin{array}{l}\text { aplastar } \\
\text { (to smash) }\end{array}$ & $\begin{array}{l}\text { aplastatu } \\
\text { (crush) }\end{array}$ & $\begin{array}{l}\text { caer } \\
\text { (to drop) }\end{array}$ \\
\hline \multirow[t]{2}{*}{7} & $\begin{array}{l}\text { dibujar } \\
\text { (to draw) }\end{array}$ & $\begin{array}{l}\text { marraztu } \\
\text { (draw) }\end{array}$ & $\begin{array}{l}\text { planificar } \\
\text { (to plan) }\end{array}$ \\
\hline & $\begin{array}{l}\text { chocarse } \\
\text { (to crash) }\end{array}$ & $\begin{array}{l}\text { txokatu } \\
\text { (choke) }\end{array}$ & $\begin{array}{l}\text { se dio un golpe } \\
\text { (got hit) }\end{array}$ \\
\hline \multirow[t]{2}{*}{8} & $\begin{array}{l}\text { subir } \\
\text { (to rise) }\end{array}$ & $\begin{array}{l}\text { igo } \\
\text { (go up) }\end{array}$ & $\begin{array}{l}\text { trepar } \\
\text { (to climb) }\end{array}$ \\
\hline & $\begin{array}{l}\text { correr } \\
\text { (to run) }\end{array}$ & $\begin{array}{l}\text { korrika egin } \\
\text { (run) }\end{array}$ & $\begin{array}{l}\text { escapar } \\
\text { (to escape) }\end{array}$ \\
\hline
\end{tabular}

